\title{
THE INFLUENCE OF MORAL JUDGMENT ON PHYSICIANS' PRESCRIPTION BEHAVIOUR
}

\author{
Sardar Md Humayun Kabir ${ }^{1 *}$, Suharni Maulan ${ }^{1}$, Noor Hazilah Abd Manaf ${ }^{1}$ and Zaireena Wan Nasir ${ }^{1}$ \\ ${ }^{1}$ Department of Business Administration, Faculty of Economics and Management Sciences, International \\ Islamic University Malaysia
}

Corresponding author: Sardar Md Humayun Kabir

Email: kabir.sardar@live.iium.edu.my

\begin{abstract}
Pharmaceutical promotion towards physicians' prescription behaviour is strongly interrelated. Identifying and addressing the ethical challenges in physicians' prescription behaviour to increase the ethical predisposition of prescribing medicines is prioritized in global health and development plans. Hence, the importance of ethics in the professionalism of healthcare practitioners is now a growing concern. The main objective of this research is to investigate the influence of moral judgment on physicians' prescription behaviour. A survey has been conducted among 152 medical practitioners from private healthcare facilities in the metropolitan area of Kuala Lumpur and Selangor states of Malaysia. Principal component analysis method in EFA and structural equation modeling technique in CFA has been used to analyze the data and validate the model. The study found that physicians' moral equity factor has a significant and positive influence on physicians' prescription behaviour whereas their relativism and contractualism factors were not significant. The empirical evidence obtained from this study would make significant contributions to advancing the current knowledge of ethical prescription behaviour. Recommendations to physicians for more ethical prescription practices have been discussed at the end of this paper.
\end{abstract}

Keywords: Physicians' prescription behaviour, Moral judgment, Moral equity, Private healthcare facilities, Malaysia

\section{INTRODUCTION}

In the pharmaceutical industry, clients and consumers fall under two distinct groups. The clients are physicians, while the consumers are patients ${ }^{1}$. In comparison to other sectors, pharmaceutical products are specialized, the promotion of which strongly depends on the relationships between pharmaceutical firms and physicians ${ }^{2}, \quad 3$. Pharmaceutical promotional activities primarily influence the choice of medications by physicians ${ }^{4}$. Low and high value gifts, free dinners, travelling costs, honorarium, sponsoring conferences and many more are provided by pharmaceutical firms, which have been questioned as indicators for a physician to administer medicines ${ }^{5},{ }^{6}$. Academics, newspapers, and medical regulatory acts are therefore constantly scrutinizing relationships between pharmaceutical firms and physicians ${ }^{7,8}$.

Globally, the total sales of pharmaceutical products were more than $\$ 1000$ billion USD in 2014 and 2015 successively ${ }^{9}$; and consequently, the pharmaceutical firms spent over $\$ 120$ billion USD on promotion of medicines in $2016^{10}$. That means, pharmaceutical firms spent over $\$ 20,000$ USD annually per physician on promotional efforts ${ }^{11}$. Such a huge promotional expenditure dramatically changes the prescription pattern of physicians ${ }^{12}$. Moreover, the pharmaceutical sales persons sometimes do unethical marketing tactics to meet the sales $\operatorname{target}^{13}$. More prescriptions mean more sales. The two most reported consents among physicians and pharmaceutical firms are ethical dilemma and prescription behaviour ${ }^{14}$. Therefore, the behaviour of the physicians in response to aggressive pharmaceutical promotions for ethical prescribing is crucial. There are relatively very few studies that have concentrated on the effect of moral judgment on the prescribing actions of physicians till date. It is thus attempted to make theoretical and functional inputs by measuring physicians' moral judgment to predict prescription behaviour.

\section{Physicians' prescription behaviour}

For someone who is under medical treatment, prescribing means setting out a rule or action. Sanyal et al. (2017) referred to it as "prescribing decisions" in reference to doctors' use of a medication in a procedure ${ }^{15}$. Ladeira et al. (2011) described it as "prescription behaviour" that shows a physician-patient partnership, regulated by the physician's (active) act or interest in the patient (receptor) ${ }^{16}$. Physicians' prescription behaviour has been described as the behaviour that relies on transactions based on some details provided about the pharmaceutical firms, their drugs, and the condition of the patient ${ }^{17}$. It has been defined as prescription loyalty behaviour when clinicians follow the medications of particular drug manufacturers based on evidence of prior successful therapies ${ }^{18}$ and write the same brand in the prescription. Thus, prescribing behaviour is the behaviour of the critical choosing of a drug by a doctor to take care of a disease. It is the outcome of the physician's decision-making process which 
includes the choosing of the right medication among the different alternatives available.

Doctors perform the jobs of clients, influencers, watchmen and decision-makers, while consumers do the purchase of products ${ }^{19}$. In order to cure a particular illness, the doctor comes to think about a drug from different sources, such as clinical preliminary results, scientific seminars, healthcare journals, books, other physicians and comprehensive detailing by pharmaceutical sales persons ${ }^{20}$. At specific points of a simple drug behavioral phase, the practitioner tends to focus more on certain sources when selecting a particular medicine. The doctor plays a crucial role in the advertisement of prescription products, as without a doctor's intervention, no moral remedy can be provided to the consumer by the retailer. Therefore, the key emphasis of this paper is on doctors and their ethical decision-making while writing prescription drugs that are influenced by pharmaceutical promotions.

\section{Moral judgment}

Moral judgment refers to deliberation, which should be morally justifiable, on potential courses of action and determined by the person ${ }^{21}$. The root of moral judgment corresponds to a philosophical argument. Rest (1986) concluded that moral decision-making starts with an understanding of the moral dilemma, and then the individual makes a moral judgment, develops a moral intention to behave, and eventually engages in moral action ${ }^{22}$. There are several factors that lead to moral behavior, and moral judgment, or deciding on what is right and what is wrong, is the most important aspect ${ }^{23}$. Ethical predisposition is perhaps the most important choice for the recognition and evaluation of moral judgment ${ }^{24}$.

Previous researchers reviewed many competing approaches to ethical predisposition, deontological ethics is one of them ${ }^{25-27}$. "Deontological" derives from the Greek Deon, "one must." Deontological theories stipulate duties that must be upheld regardless of their results: true rights must be considered, and conduct can be denied without being asked for. Deontology is primarily identified with Immanuel Kant, who believed that good will was the greater good, and morally acceptable acts are those done with a sense of obligation ${ }^{28}$. Reidenbach and Robin (1988), Granitz and Loewy (2007) found that to prevent fraud or cheating, people rely on moral judgment that is based on the concepts of deontology ${ }^{29}, 30$. In ethical organizational structure, decisions are considered to be based on structured standards for behaviour ${ }^{31}$ and moral judgment is required to be based on a rigid accordance with the organizational rules and regulation. The principles of deontology therefore outline strict behaviour rules. Moral judgment is considered important for moral decision-making and action $^{32}$, and it reflects the mechanism involved in the process of the ethical decision-making model of Rest (1986), i.e., judging what is morally correct ${ }^{33}$. Deontology holds the position that, regardless of the consequences, the legal status of an action should be determined on the basis of the features of the action ${ }^{34}$.

\section{Dimensions of moral judgment}

Moral judgment forms moral actions (e.g., consequentialism, formalism) which focused on ethical or duty-based approaches to morality ${ }^{35}$, ${ }^{36}$. For moral judgment and decision-making, a systematic, coherent paradigm does not exist, but in the last few decades, scholars have made significant empirical advances in moral judgment and decision-making. The Multidimensional Ethics Scale (MES) is the evaluative criteria that scholars commonly use to render a moral judgment ${ }^{37},{ }^{38}$. Initially, Reidenbach and Robin $(1988)^{29}$ created the MES of 33 elements based on a factual study of five ethical theories: justice, deontology, relativism, utilitarianism, and egoism to assess people's moral reactions. The scale gives insights into the philosophies or rationales driving ethical decisions. The scale was later reduced to 8-items by Reidenbach and Robin $(1990)^{37}$ based on the philosophies of justice, relativism and deontology that measured three orthogonal constructs: (i) a moral equity dimension, (ii) a relativism dimension, and (iii) a contractualism dimension.

\section{Physicians' moral judgment and prescription behaviour}

Different experiments have found that moral judgment has a profound influence on the behavioral system. Moral judgment starts with an appreciation of the moral dilemma ${ }^{22}$. The individual then makes a moral decision, develops an intention to behave morally, and eventually engages in moral behaviour. Many observational studies identified with moral judgment found that persons who judge an action to be highly moral are bound to perform moral actions ${ }^{39}, 40$. In healthcare sector, moral judgment is comparatively a new area of interest. There are many evidences that shows that healthcare services are heavily skewed by physicians in partnership with pharmaceutical firms. Pharmaceutical firms have an overwhelming propensity to indulge in misleading advertising practices by offering tangible rewards for physicians to recommend branded medications ${ }^{41}$. According to Rahman et al. (2014), because of unethical activities, there is a deterioration of morality among these two groups ${ }^{42}$. Therefore, owing to such partnerships between pharmaceutical firms and doctors, the dispute between the ethical interest of a practitioner and his/her financial self-interest has been scrutinized ${ }^{43,14}$. 
The ethical challenges in prescribing behaviour have been established in few studies ${ }^{44,}$ 45. A comparative analysis by a group of researchers on physicians and pharmaceutical sales representatives (PSRs) studied expectations and attitudes towards the promotion of pharmaceutical firms and found that about thirty-six percent of doctors requested benefits from PSRs ${ }^{41}$. But when the researchers crosschecked the views of PSRs, they found that about sixty-four percent of doctors asked benefits such as leisure trips and vehicles. Thus, pharmaceutical promotion targeted at doctors has raised moral concerns, such as the distribution of presents, samples, activities, etc. According to deontological ethics, duties of a person were of considerable significance and consequences did not explain the means ${ }^{46}$. Here the person is the doctor. The main point in making effective choices when prescribing is to look at various options in terms of their potential to meet the most significant ethical medication prescribing goals.

Studies that have investigated ethical decisionmaking typically reflect on the ethical rationale or excuse that people use in morally challenging circumstances to justify their choices and actions. It is believed that these explanations are originating from particular ethical philosophies that came from the fundamental principles used for moral judgment. In previous studies, it was found that moral judgment is a good predictor of moral behaviour ${ }^{47}$. Subsequently, it can be argued that moral judgment is ultimately related to moral behaviour of physicians. Therefore, to recognize the effect of ethical dilemma on the prescription action of the doctor, the relationships between moral judgment dimensions and physicians' prescription behaviour has been conceptualized.

\section{METHODS}

To fulfil the purpose of the study, Malaysia has been used as the study setting. The medical doctors working in public hospitals and clinics prescribe medicines from the list of government approved medicine list and pharmaceutical promotion towards physicians working in public hospitals and clinics are not in their scope. Therefore, the focus of this study was on doctors who work in private hospitals and clinics in Malaysia, as they are the target audience for pharmaceutical industry promotions. So, the target population was 14,483 medical doctors including general physicians and general practitioners working in private healthcare facilities in Malaysia ${ }^{48}$. For data collection purpose, the clinics and hospitals were being selected randomly from the list of total private clinics and hospitals provided by KKLW (Rural and Regional Development Ministry) and Ministry of Health $(\mathrm{MOH})$ respectively. Non-probabilistic convenience sampling technique has been used to select the respondents from hospitals and clinics due to the fact that all medical professionals are not practicing doctors. As a result, general physicians and general practitioners who are practicing in the private hospitals or clinics located in Klang Valley and visited by pharmaceutical sales persons has been selected. Klang Valley is a major area in Malaysia which is centered in Kuala Lumpur and includes its adjoining cities and towns in the state of Selangor.

To achieve the objective of the research, a selfadministered, close-ended, structured questionnaire has been used on a scale of 1 to 5 where 1 is strongly disagree and 5 is strongly agree ${ }^{49}$. To investigate the relationship between physicians' prescription behaviour (PPB) and moral judgment $(M J)$, both the constructs proposed in this study has been measured using multiple items based on previous studies. PPB questionnaires (5 items) were adapted from Waheed et al. (2011) 17 and MJ questionnaires (10 items) were adapted from Love et al. $(2018)^{50}$. To reduce social desirability bias, the survey was conducted assuring confidentiality and anonymity of the respondents and using indirect (passive) questioning format ${ }^{51}$.

Data collection for the survey has been conducted over four months of time from November 2019 to February 2020. The researcher visited the private medical centers (clinics, hospitals) to distribute the hard copy questionnaires among selected general practitioners and general physicians during different time of the day based on the doctor's availability. Due to the busy schedule of medical doctors, the researcher had to visit three to five times in most of the clinics and hospitals. A lack of cooperation from some respondents were noticed due to their time constraint. There were some rejection from few respondents due to their temporary job status (Locum doctors).

For data analysis, the study also considered issues related to data screening prior to further analysis, such as the treatment of incomplete data, multicollinearity and detection of outliers and normality issues. Cronbach's alpha, composite reliability, convergent validity and discriminant validity were measured to find the reliability and validity of the constructs. As MJ questionnaires were rarely used in previous studies to predict PPB, exploratory factor analysis (EFA) with principle component analysis method in SPSS has been used to get the best estimates. Then, confirmatory factor analysis (CFA) with structural equation modeling technique in AMOS has been used to evaluate the structural model of the study and getting the results of the path coefficients among the relationships of $M J$ and PPB. 
In SPSS, Cronbach's Alpha is generally used to measure the reliability or internal consistency of questionnaire items. After running the reliability test, it was found that for both constructs, the Cronbach's Alpha value was greater than 0.8 (for moral judgment, $a=0.837$ and for physicians' prescription behaviour, $\mathrm{a}=0.851$ ) which means that both the constructs used in this research are reliable enough ${ }^{52}$.

\section{RESULTS}

In this study, a total of 152 valid responses were received with a response rate of $50.6 \%$. After running descriptive statistics in SPSS, the demographic information including their gender, age, institution category, qualification, and years of experience of the respondents are presented in Table 1. Among the respondents, mostly were female (57.9\%), aged between 31 to 40 years $(42.8 \%)$, practicing in clinics $(63.2$ $\%)$, general physicians (66.4\%), with 1 to 10 years of experience (56.6 \%).

Table 1. Demographic characteristics of respondents

\begin{tabular}{|c|c|c|c|}
\hline Variable & Category & Frequency & Percent (\%) \\
\hline \multirow[t]{2}{*}{ Gender } & Male & 64 & 42.1 \\
\hline & Female & 88 & 57.9 \\
\hline \multirow[t]{4}{*}{ Age } & 21 to 30 & 23 & 15.1 \\
\hline & 31 to 40 & 65 & 42.8 \\
\hline & 41 to 50 & 51 & 33.6 \\
\hline & More than 50 & 13 & 8.60 \\
\hline \multirow[t]{2}{*}{ Institution Category } & Hospital & 56 & 36.8 \\
\hline & Clinic & 96 & 63.2 \\
\hline \multirow{2}{*}{ Qualification } & GP & 101 & 66.4 \\
\hline & Specialist & 51 & 33.6 \\
\hline \multirow[t]{3}{*}{ Years of Experience } & 1 to 10 & 86 & 56.6 \\
\hline & 11 to 20 & 52 & 34.2 \\
\hline & More than 20 & 14 & 9.2 \\
\hline
\end{tabular}

\section{Exploratory factor analysis}

During EFA, the Kaiser-Meyer-Olkin measure of sampling adequacy was found 0.803 which is considered as highly satisfactory 53,54 . Moreover, the value of Bartlett's Test of Sphericity $[\times 2=$ 877.643; df $=105 ; p=0.000]$ was found significant, rejecting the null hypothesis that the correlation matrix was an identity matrix.

With principal component analysis extraction method, it was found that three components had Eigenvalues greater than one and the rest of the components had Eigenvalues less than one. It means three components should be retained. After analyzing the data again in SPSS through fixed number of factors (three) and suppressing small coefficient values to less than 0.4 , it was found that the Component Correlation Matrix is orthogonal. Again, the Varimax option in SPSS for analyzing orthogonal matrix was checked. From the Rotated Component Matrix, the number of items $(10$, initially it was 15$)$ which are related to the factors were determined. The items for relativism dimension of moral judgment were cross-loaded with moral equity and contractualism dimensions and therefore has been eliminated. According to Hair et al. (2010), a satisfactory value of factor loading for each item over 0.7 is significant to confirm the meaningfulness of the questionnaire ${ }^{52}$.
Therefore, factor loadings with values over 0.7 for moral equity and contractualism dimensions were selected for further analysis. Table 2 represents the detail of communalities, eigenvalues, \% of variances and factor loadings in rotated component matrix explained by the dimensions of moral judgment (MJ) and physicians' prescription behaviour (PPB).

After EFA, for both constructs, the Cronbach's Alpha value was measured again (for moral judgment, $a=0.752$ and for physicians' prescription behaviour, $a=0.864$ ) and found within acceptable range ${ }^{52}$.

\section{Confirmatory factor analysis}

There are varieties of indicators that tells how good the model fits in Structural Equation Model $^{55}$. In this analysis, the Chi-Square, Root Mean-Square Error of Approximation, and Comparative Fit Index values were checked to evaluate the model fit in AMOS. From Figure 1, it was found that CMIN is 42.804 , CMIN/DF is 1.338 , RMSEA is $0.047, \mathrm{CFI}$ is 0.980 and all the indicators were statistically significant $(p=$ 0.000). Therefore, based on the RMSEA value (RMSEA < 0.05) and the CFI value $(C F I>0.90)$, the model fit is found satisfactory ${ }^{56}$. 
Malaysian Journal of Public Health Medicine 2021, Vol. 21 (3):96-105

Table 2. Factor analysis results

\section{Components}

Factors Items Communalities Eigenvalues \% of Variance

\begin{tabular}{lll}
\hline 1 & 2
\end{tabular}

\begin{tabular}{llllrr}
\hline MJ & MJ1 & .599 & 4.202 & 28.011 & .716 \\
(Moral Equity) & MJ2 & .701 & & .818 \\
& MJ3 & .547 & & .731
\end{tabular}

$\begin{array}{llllll}\text { MJ (Contractualism) } & \text { MJ7 } & .726 & 3.133 & 20.887 & .845 \\ & \text { MJ8 } & .552 & & & .729 \\ & \text { MJ9 } & .539 & & & .724 \\ \text { PPB } & \text { PPB1 } & .709 & 1.442 & 9.614 & .840 \\ & \text { PPB2 } & .664 & & .808 \\ & \text { PPB3 } & .694 & & .824 \\ & \text { PPB4 } & .687 & & .823 \\ \end{array}$

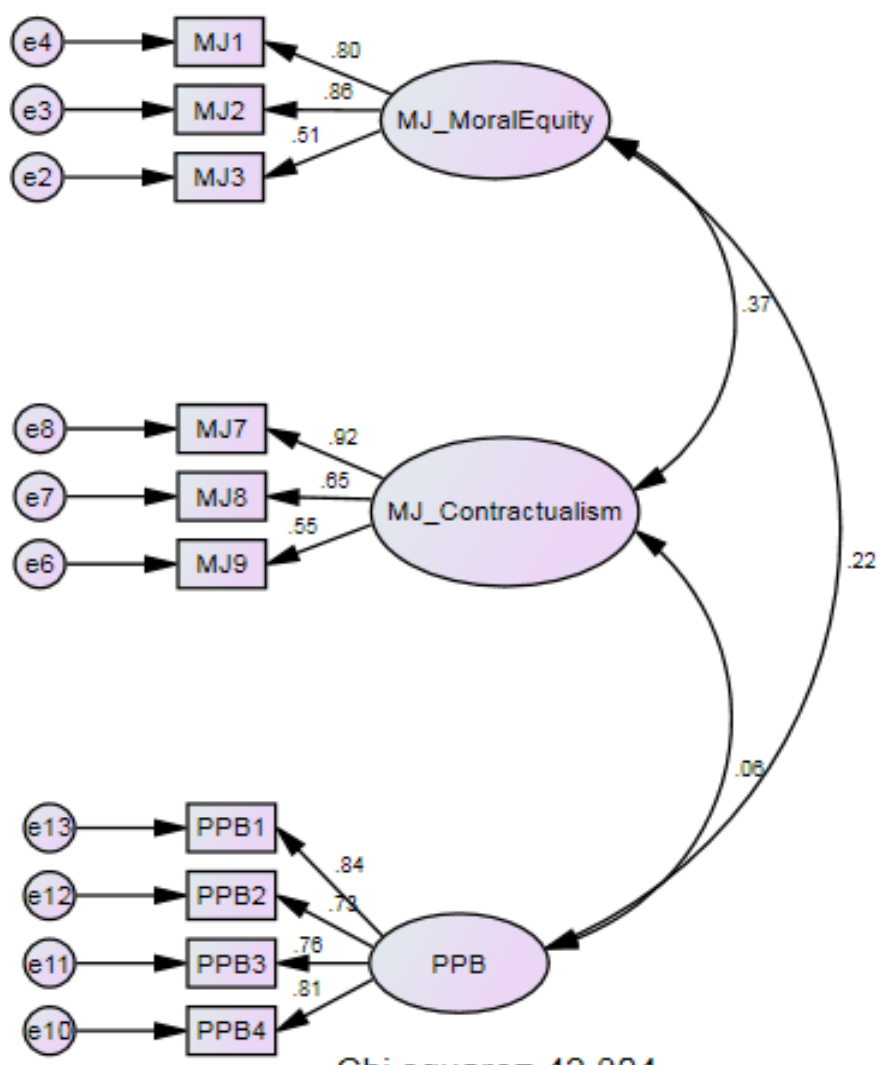

\footnotetext{
Chi square $=42.804$

$\mathrm{Df}=32$

Normed chi square $=1.338$

$\mathrm{CFI}=.980$

RMSEA $=.047$
}

Figure 1. Structural model 
Table 3 shows composite reliability, convergent validity, and the discriminant validity of the constructs. The composite reliabilities ranged from .79 to .86 , which is considered very good ${ }^{52}$. Average variance extracted (AVE) is a measure of the convergent validity of the model's constructs and ranged from .50 to .58 , so all constructs exhibit convergent validity ${ }^{52}$. The Fornell-Larcker (1981) criterion assesses discriminant validity between the constructs and also within the stipulated range ${ }^{57}$. Therefore, it is concluded that the model's factors (MJ_Moral equity, MJ_Contractualism and PPB) were reliable and valid, so the next step was to examine the structural model.
Figure 2 represents the measurement model with normed chi-square was 1.731 , CFI was 0.956 , RMSEA was .070 and the significance level for coefficients was $p=.006$. The measurement model was therefore also have satisfactory goodness of $\mathrm{fit}^{52}$.

Table 4 shows the regression results for the Covariance-Based Structural Equation Modeling. The critical ratio and significance of path coefficients were used as the basis for commenting on the relationships proposed in the model. Therefore, it can be said that the path, PPB <--- MJ_MoralEquity is supported whereas the path, PPB <--- MJ_Contractualism is not supported based on the results of the analysis. Here, the threshold is $C R \geqslant \pm 1.96$ and the path is significant at $\mathrm{p} \leq 0.05$ level ${ }^{52}$.

Table 3. Reliability and validity examinations

\begin{tabular}{llll}
\hline & MJ_MoralEquity & MJ_Contractualism & PPB \\
\cline { 2 - 4 } Average Variance Extracted & 0.572 & 0.589 & 0.509 \\
Composite Reliability & 0.799 & 0.811 & 0.863 \\
\hline Fornell-Larcker Criterion & MJ_MoralEquity & MJ_Contractualism & PPB \\
MJ_MoralEquity & 0.756 & & \\
MJ_Contractualism & 0.374 & 0.768 & \\
PPB & 0.217 & 0.059 & 0.713
\end{tabular}

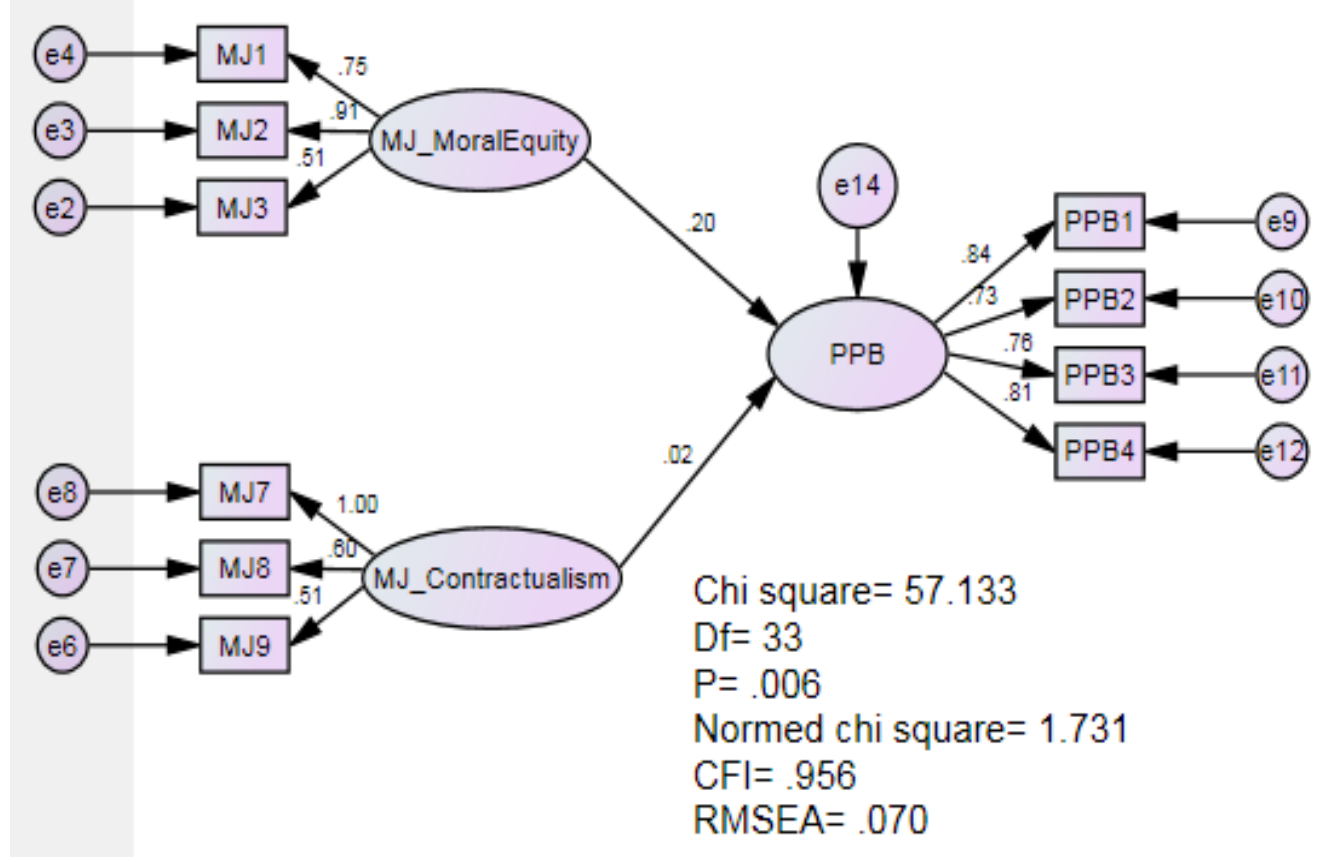

Figure 2. Measurement model 
Table 4. Covariance: Default Model
Paths
Estimate
S.E.
C.R.
P

\begin{tabular}{|c|c|c|c|c|c|c|}
\hline PPB & $<---$ & MJ_MoralEquity & 0.544 & 0.266 & 2.046 & 0.041 \\
\hline PPB & $<---$ & MJ_Contractualism & 0.051 & 0.222 & 0.229 & 0.819 \\
\hline
\end{tabular}

\section{DISCUSSION}

The results of the EFA suggested the existence of a two-factor solution for moral judgment which are Moral Equity and Contractualism to predict physicians' prescription behaviour. The Relativism factor was eliminated due to interfactor correlations with Moral Equity and Contractualism. The results of the CFA showed that Moral Equity is the most important and has the largest standardized Beta, indicating its relative importance. The results also showed that the impact of Contractualism on the ethics measure is small and not significant. However, the total scale explained about $48 \%$ of the variance in the ethical judgment measure of physicians while prescribing.

In prescription behaviour studies, the use of moral judgment is very recent. That's why, this investigation is one of the primitives for physician's prescription behaviour studies on moral ground. Results from this study showed significant positive relationship between moral judgment (i.e., Moral Equity) and physicians' prescription behaviour. The three statements that load on Moral Equity ("Solutions to ethical problems are usually simple", "A person's actions should be described in terms of being right or wrong", and "Uttering a falsehood is wrong because it wouldn't be right for anyone to lie") represent acceptable scale reliability $(\alpha=$ $0.759)$. The other three statements that load on Contractualism are found insignificant in predicting physicians' prescription behaviour. All these statements (Moral Equity and Contractualism) represent the formalism subscale. It captures the tendency of an individual to make ethical choices based on a set of rules which determine whether a decision or behavior is good or bad where consequences are irrelevant ${ }^{50}$.

Moral judgment is favorable to good moral reasoning as one must decide for oneself what is good and bad, right and wrong. One must ensure to make the right choices while taking any decisions. Historically, researchers have addressed this issue for personal and professional behaviour. Ethical behaviour, particularly in professional lives depends on moral reliability which is, being capable of acting on sound moral judgments ${ }^{58}$. Physicians' should care about making good, reliable judgments if they care about doing the right thing. Oftentimes, physicians' make split-second decisions while prescribing medicines and even in that time they must think procedures to produce good, reliable prescriptions. Thus, good judgment can regulate moral decision-making in physicians' prescription behaviour considering physicians' cognitive, selfmanagement, social and motivational abilities to increase for better moral judgment.

\section{Implications}

Physicians need to have moral consciousness to identify inconsistencies and unethical behaviour governing their interaction with pharmaceutical sales representatives. It is necessary to recognize a moral fault in the beginning of a relationship. Moral ideas are usually complicated, and therefore, physicians should have clear and distinct ideas on moral issues. Even when they write the prescription, doubts may arise. If physicians are morally judgmental then moral judgment must settle down these doubts and produce fair prescriptions. Physicians need to prioritize the relative importance of competing moral issues and considerations. For example, while prescribing, what is more important for a physician, reputation of the drug manufacturer or the drug quality. Physicians should manage setting priorities as to such moral questions to consider in the first place. Physicians need to have self-control on their intentional actions and actual judgments. For example, physicians might recognize the moral imperative to prescribe less expensive and/or more effective drugs, yet, prescribing the ones which are more expensive and/or less effective. Such kind of weakness in prescription behaviour can be reduced by having self-control to consciously-held moral judgments. Biasness is very common in prescription behaviour which manipulates physicians' moral way of thinking. For example, prescribing the highly promoted medicine irrespective of quality and/or sufficient clinical evidences. Therefore, physicians need to be aware for avoiding such unethical behaviour. Physicians can use more systematic approach (for example, decision procedures) to deal with certain problems like bias. 


\section{CONCLUSION}

Moral judgment requires engagement with decision procedures - awareness of the interest, and willingness to avoid such interest. Therefore, physicians need to be trained on moral decision-making guidelines governing their ethical interactions with other stake holders, such as those of the Royal Australasian College of Physicians ${ }^{59}$. It is therefore important that physicians should recognize the issue and take the recommendations while prescribing to increase ethical prescription practices.

\section{Conflict of interest}

There is no conflict of interest as declared by the authors.

\section{Ethical Endorsement and Investigator Agreement \\ The study has been conducted based on the ethical guidelines of National Medical Research Register (NMRR) in Malaysia. NMRR ID number was issued to the researcher as reference.}

\section{REFERENCES}

1. James C, Peabody J, Solon O, et al. An unhealthy public-private tension: Pharmacy ownership, prescribing, and spending in the Philippines. Health affairs 2009; 28(4):1022-1033.

2. Shamim-ul-Haq S, Ahmed RR, Ahmad N, et al. Factors Influencing Prescription Behavior of Physicians. The Pharma Innovation Journal 2014; 3(5):30-35.

3. Ali MM, Mohaidin Z, Models and theories of prescribing decisions: A review and suggested a new model. Pharmacy Practice 2017; 15(2):990.

4. Wei $M$, Delbaere $M$, Do consumers perceive their doctors as influenced by pharmaceutical marketing communications? A persuasion knowledge perspective. International journal of pharmaceutical and healthcare marketing 2015; 9(4):330-348.

5. Khazzaka M, Pharmaceutical marketing strategies' influence on physicians' prescribing pattern in Lebanon: Ethics, gifts, and samples. BMC Health Services Research 2019; 19(1):1-11.

6. Skandrani $\mathrm{H}$, Sghaier $M$, The dark side of the pharmaceutical industry. Marketing intelligence \& planning 2016; 34(7):905926.
7. Fickweiler F, Fickweiler W, Urbach E, Interactions between physicians and the pharmaceutical industry generally and sales representatives specifically and their association with physicians' attitudes and prescribing habits: A systematic review. BMJ Open 2017; 7(9):e016408. doi:10.1136/bmjopen2017-016408

8. Alves TL, Lexchin J, Mintzes B, Medicines Information and the Regulation of the Promotion of Pharmaceuticals. Science and Engineering Ethics 2019; 25(4):11671192.

9. Statista Report (2015). Revenue of the worldwide pharmaceutical market from 2001 to 2015 (in billion U.S. dollar). Retrieved from:

https://www.statista.com/statistics/263 102/pharmaceutical-market-worldwiderevenue-since-2001/

10. Lexchin J, Pharmaceutical company spending on research and development and promotion in Canada, 2013-2016: a cohort analysis. Journal of Pharmaceutical Policy and Practice 2018; 11(5):1-6.

11. Weiss J, Medical marketing in the United States: A prescription for reform. The George Washington law review 2010; 79(1):260-292.

12. Zaki NM, Pharmacists' and physicians' perception and exposure to drug promotion: A Saudi study. Saudi pharmaceutical journal: the official publication of the Saudi Pharmaceutical Society 2014; 22(6):528-536. https://doi.org/10.1016/j.jsps.2014.02.0 $\underline{08}$

13. Hirschler B, Bribery scandal slashes GlaxoSmithKline's Chinese drug sales. Thomson Reuters 2013; 23 October.

14. Latten $T$, Westra $D$, Angeli $F$, et al. Pharmaceutical companies and healthcare providers: Going beyond the gift: An explorative review. PLoS one 2018; 13(2):e0191856.

15. Sanyal SN, Datta SK, Banerjee AK, Factors influencing prescribing decisions among physicians: an empirical study on generic drugs. International Journal of Pharmaceutical and Healthcare Marketing 2017; 11(4):330-360. 
16. Ladeira W, Dalmoro M, Maehler A, et al. Drug prescription practices in Brazil: A structural equation model. International Journal of Pharmaceutical and Healthcare Marketing 2011; 5(4):262278.

17. Waheed KA, Jaleel $M$, Laeequddin $M$, Prescription loyalty behavior of physicians: an empirical study in India. International Journal of Pharmaceutical and Healthcare Marketing 2011; 5(4):279-298.

18. Campo K, De Staebel O, Gijsbrechts E, et al. Physicians' decision process for drug prescription and the impact of pharmaceutical marketing mix instruments. Health marketing quarterly 2005; 22(4):73-107.

19. Abratt R, Lanteigne J, Factors influencing general practitioners in the prescription of homeopathic medicines. South African Journal of Business Management 2000; 31(3):91-97.

20. Brewster J, What information sources do physicians value for staying abreast of new medical developments?. Kantar Media 2014.

21. Garrigan B, Adlam ALR, Langdon PE, Moral decision-making and moral development: Toward an integrative framework. Developmental review 2018; 49(March):80-100.

22. Rest JR, Moral development: Advances in research and theory. New York: Praeger 1986.

23. Kohlberg L, The philosophy of moral development. San Francisco: Harper \& Row 1981.

24. Reynolds SJ, Ceranic TL, The effects of moral judgment and moral identity on moral behavior: An empirical examination of the moral individual. The Journal of applied psychology 2007; 92(6):1610-1624.

https://doi.org/10.1037/00219010.92.6.1610

25. Baron MW, Pettit P, Slote M, Three methods in ethics. Malden: Blackwell Publishers Inc 1997.

26. Premeaux SR, The current link between management behavior and ethical philosophy. Journal of business ethics 2004; 51 (May):269-278.
27. Lahdesmati $M$, When ethics matters interpreting the ethical discourse of small nature - based entrepreneurs. Journal of business ethics 2005; 61(1):55-68.

28. Kant I, Groundwork of the metaphysics of morals. Edited by Mary Gregor. Cambridge: Cambridge University Press 1998.

29. Reidenbach RE, Robin DP, Some initial steps toward improving the measurement of ethical evaluations of marketing activities. Journal of business ethics 1988; 7(11):871-879.

30. Granitz N, Loewy D, Applying ethical theories: Interpreting and responsibility to student plagiarism. Journal of business ethics 2007; 72(3):293-306.

31. Victor B, Cullen JB, The organizational bases of ethical work climates. Administrative science quarterly 1988; 33(1):101-125.

32. Pettifor JL, Estay I, Paque S, Preferred strategies for learning ethics in the practice of a discipline. Canadian psychology 2000; 43(4):260-269.

33. Trevino LK, Moral reasoning and business ethics: Implications for research, education and management. Journal of business ethics 1992; 11(5/6):445-459.

34. Bartels DM, Bauman CW, Cushman FA, et al. Moral Judgment and Decision Making. In: G. Keren \& G. Wu (Eds.) Blackwell Reader of Judgment and Decision Making. Malden, MA: Blackwell 2014.

35. Trevino LK, Weaver GR, Reynolds SJ, Behavioral ethics in organizations: A review. Journal of management 2006; 32(6):951-990.

36. Kant I, Ethical philosophy. 2nd ed., J. W. Ellington, Trans. Indianapolis, IN: Hackett Publishing 1994.

37. Reidenbach R, Robin D, Toward the development of a multi-dimensional scale for improving evaluations of business ethics. Journal of Business Ethics 1990; 9:639-653.

38. Gupta S, A multidimensional ethics scale for Indian managers' moral decision making. Electronic Journal of Business Ethics and Organization Studies 2010; 15(1):5-14. 
39. Ajzen I, Fishbein M, Understanding attitude and predicting social behavior. Englewood Cliffs, NJ: Prentice Hall 1980.

40. Hunt S, Vitell S, A general theory of marketing ethics. Journal of micromarketing 1986; 6(1):5-16.

41. Khan N, Naqvi A, Ahmad $R$, et al. Perceptions and attitudes of medical sales representatives (MSRs) and prescribers regarding pharmaceutical sales promotion and prescribing practices in Pakistan. Journal of young pharmacists 2016; 8(3):244-250. 10.5530/jyp.2016.3.13.

42. Rahman MK, Khan AH, Jalil A, Ethical implications of sales promotion in Malaysia. Islamic perspective 2014; 2(1):13-27.

43. Mohiuddin M, Rashid SF, Shuvro MI, et al. Qualitative insights into promotion of pharmaceutical products in Bangladesh: how ethical are the practices?. BMC medical ethics 2015; 16(1):80. https://doi.org/10.1186/s12910-015$\underline{0075-z}$

44. Allman RL, The relationship between physicians and the pharmaceutical industry: ethical problems with the every-day conflict of interest. HEC forum: An interdisciplinary journal on hospitals' ethical and legal issues 2003; 15(2):155-170.

https://doi.org/10.1023/a:102490100849 $\underline{5}$

45. Sillup GP, Porth SJ, Ethical issues in the pharmaceutical industry: An analysis of US newspapers. International journal of pharmaceutical and healthcare marketing 2008; 2(3):163-180.

46. Kant I, Critique of pure reason. Edited by Paul Guyer and Allen W. Woods. Cambridge: Cambridge University Press 1998a.

47. Guglielmo S, Moral judgment as information processing: an integrative review. Frontiers in psychology 2015; 6:1637.

https://doi.org/10.3389/fpsyg.2015.016 $\underline{37}$

48. MOH: Malaysian statistics on medicines (2011 - 2014). Ministry of Health, Pharmaceutical Services Division 2017.

49. Vancelik S, Beyhun NE, Acemoglu H, et al. Impact of pharmaceutical promotion on prescribing decisions of general practitioners in Eastern Turkey. BMC Public Health 2007; 7(122):1-8.

50. Love E, Salinas TC, Rotman JD, The ethical standards of judgment questionnaire: Development and validation of independent measures of formalism and consequentialism. Journal of business ethics 2018; 161(1):115-132.

51. Grimm P, Social desirability bias. In: Wiley International Encyclopedia of Marketing (eds J. Sheth and N. Malhotra) 2010.

doi:10.1002/9781444316568.wiem02057

52. Hair JF, Black WC, Babin BJ, et al. Multivariate data analysis (Seven ed.). Upper Saddle River, NJ Prentice Hall: Pearson 2010.

53. Frohlich MT, Westbrook R, Arcs of integration: An international study of supply chain strategies. Journal of Operations Management 2001; 19:185200. https://doi.org/10.1016/S02726963(00)00055-3

54. Chua YP, Ujian Regresi, Analisis Faktor, dan Analisis SEM. Shah Alam: McGraw Hill Education 2014.

55. Kenny DA, Kaniskan B, McCoach DB, The performance of RMSEA in models with small degrees of freedom. Sociological Methods \& Research 2015; 44(3):486507. https://doi.org/10.1177/004912411 $\underline{4543236}$

56. Hair JF, Black B, Babin BJ, et al. Multivariate Data Analysis 6th Edition. Pearson International Edition 2006.

57. Fornell C, Larcker DF, Evaluating structural equation models with unobservable variables and measurement error. Journal of Marketing Research $1981 ; 18(1): 39-50$.

58. Schaefer GO, Savulescu J, Better minds, better morals: A procedural guide to better judgment. Journal of posthuman studies: philosophy, technology, media 2017; $1(1): 26-43$. https://doi.org/10.5325/jpoststud.1.1.0 $\underline{026}$

59. Othman N, Vitry Al, Roughead EE, et al. Doctors' Views on The Quality Of Claims Provided By Pharmaceutical Representatives: A Comparative Study In Malaysia And Australia. Journal of Taibah University Medical Sciences 2015; 10(4):471-480. 